\title{
Menthol: putting the pieces together
}

\author{
Youn Ok Lee, ${ }^{1}$ Stanton A Glantz ${ }^{2}$
}

${ }^{1}$ Center for Tobacco Control Research and Education, University of California, San Francisco, California, USA ${ }^{2}$ Department of Medicine, Center for Tobacco Control Research and Education, University of California, San Francisco, California, USA

\section{Correspondence to}

Professor Stanton A Glantz, University of California, San Francisco, CA 94143-1390, USA:

glantz@medicine.ucsf.edu

Received 14 February 2011 Revised 15 February 2011 Accepted 16 February 2011

\begin{abstract}
Objective To integrate information on cigarette companies' understanding and use of menthol as summarised in published research based on previously internal tobacco industry documents with results from large population-based surveys of tobacco use and other independent sources.
\end{abstract}

Data sources Papers published in this supplement of Tobacco Control, together with papers identified using PubMed searches.

Results Tobacco companies shaped consumer perceptions of menthol cigarettes. Menthol is not just a flavouring agent. Cigarette companies use menthol's ability to mask irritation and provide sensory effects to make menthol cigarettes appeal to youth and healthconcerned smokers, in part because menthol makes low-tar cigarettes more palatable. Consistent with targeted marketing, youths, women and African Americans disproportionately smoke menthols. There appear to be complex interactions with addictive effects of nicotine. The ubiquitous addition of menthol by tobacco companies to over $90 \%$ of all tobacco products, whether labelled 'menthol' or not, demonstrates that menthol is not simply a flavour or brand. Menthol imparts sensory characteristics to cigarettes and has a complex interaction with nicotine that affects smoking behaviour whether it is perceived or not, or whether cigarettes containing menthol are marketed as 'menthol' or not. Adding menthol increases fine particles in cigarette smoke, which have immediate adverse effects on the risk of heart attack.

Conclusion Information from industry documents, confirmed by independent scientific literature, consistently demonstrates that menthol increases population harm from smoking by increasing initiation and reducing cessation in some groups. Menthol facilitates and increases smoking, which causes disease and death.

On 22 June 2009, President Barack Obama signed the Family Smoking Prevention and Tobacco Control Act, giving the Food and Drug Administration (FDA) authority to regulate tobacco products. ${ }^{1}$ The law instructed the FDA to ban use of candy, fruit and spice flavours in cigarettes, but not menthol. During the Congressional debate the menthol exemption drew a strong response from seven former Secretaries of Health and Human Services and one Surgeon General who called it discriminatory against African Americans and said that the bill "cav(ed) to the financial interests of tobacco companies ... (and sent) the message that African American youngsters are valued less than white youngsters'. 2 Owing to the public outcry following the exclusion of menthol from the list of banned additives, Congress amended the bill to require that the FDA to prepare a study of menthol by March 2011. This study could be-but does not have to be-the first step towards regulating or eliminating menthol from cigarettes and other tobacco products.

The first menthol cigarette was created in 1925 by Lloyd 'Spud' Hughes who, while suffering from a cold, stored menthol crystals along with his tobacco and discovered the next day that he had created a mentholated cigarette. ${ }^{3}$ Since then, the tobacco companies have known of menthol's ability to mask the harshness, increase the ease of smoking and provide a cooling sensation that appeals to many smokers ${ }^{4} 5$ Prior to 1956 , sales of menthol cigarettes represented about $3 \%$ of the overall cigarette market in the USA, ${ }^{6}$ reaching $20 \%$ in 2006..$^{\text {. }}$ Menthol is added to over $90 \%$ of all tobacco products whether labelled 'menthol' or not. $^{8}$ (Internationally, tobacco companies confirmed in the 1990s that in Asia, menthol cigarettes are important in attracting beginning smokers and young people because of their preferences for lighter taste. ${ }^{9}$ ) As the tobacco companies recognised menthol's value for recruiting and retaining smokers, they conducted research to refine their marketing strategies and the cigarettes themselves to improve their appeal.

We know these facts because, as a result of litigation, we have access to over 60 million pages of previously internal tobacco industry documents. Indeed, in 2006, 3 years before Congress granted the FDA authority to regulate tobacco products, RJ Reynolds anticipated that the FDA would use these documents to understand why and how the industry makes and sells its products:

\section{An industry has developed around the analysis of Tobacco company documents (typically produced as a part of litigation activities). This activity would likely proceed since it is felt that it has retrospectively demonstrated industry intentions and provides a means to ensure industry activities are kept in check. ... The FDA would likely contract with such groups to perform these tasks using documents made available by the Industry. ${ }^{10}$}

As RJ Reynolds anticipated, many investigators, ${ }^{4-6} 9$ 11-14 including several supported by the FDA, ${ }^{8}{ }^{15-19}$ have used the documents to understand why and how the cigarette companies use menthol to sell cigarettes.

This review compares the conclusions from investigations into tobacco companies' knowledge about menthol with results from large populationbased surveys conducted by non-industry investigators. A remarkably consistent picture emerges, which shows that consumer perceptions and use of menthol cigarettes are largely consistent with the companies' planning. The information in the unlocked scheme, see http:/ about/unlocked.xhtml 
documents, however, goes beyond the information obtained from independent population surveys to demonstrate that menthol-even at levels so low that they are not perceived by the smoker-also has important effects on smoking behaviour.

\section{THE TOBACCO COMPANIES MANIPULATED MENTHOL CONTENT AND MARKETING TO TARGET INITIATES AND YOUTH}

Menthol cigarettes were not introduced to appeal to youth, but by the mid-1970s industry market research began to reveal that they were popular among young smokers because they were perceived as less harsh and easier to smoke. ${ }^{11}{ }^{18}$ To capitalise on these desirable characteristics, the companies manipulated menthol levels and used targeted marketing to enhance the menthol cigarettes' appeal to this population. ${ }^{18}$

A 1977 Philip Morris study found that the median age for Lorillard Tobacco Company's Newport King smokers was the youngest for all cigarette brands: 24.8 years old compared with 38.0 for all smokers. ${ }^{6}$ Newport's success in the young adult market demonstrated that mentholated cigarettes with relatively low menthol content appealed disproportionately to young people led other companies to develop low menthol cigarettes. By the 1980s all major menthol brands had low menthol varieties to target this market. ${ }^{11}$ According to company research in the 1980s, half of Newport smokers were under 25 and young smokers identified Newport as smoother, milder and less harsh than Brown and Williamson's Kool menthols, which had higher levels of mentholation. ${ }^{6}$

Tobacco companies developed marketing to target young potential menthol smokers. Lorillard's competitors attributed Newport's success to its appeal among younger smokers. ${ }^{11}{ }^{18}$ By the 1990s Lorillard had built Newport into the most successful menthol brand with its youthful and fun marketing campaign that often depicted people doing childlike, silly activities. ${ }^{6}$ Following Newport's success, other menthol brands, including RJ Reynolds' Salem, copied the use of young people in their marketing materials. ${ }^{18}$

Independent research confirms that menthol cigarette use is more common among younger and newer teen smokers. ${ }^{20-22}$ The 2004-2008 National Survey on Drug Use and Health (NSDUH) shows the youngest current smokers in the study (age $12-17)$ had the highest past month menthol cigarette use. ${ }^{22}$ Even though cigarette use declined between 2004 and 2008, the fraction of smokers aged 12-17 years reporting past month menthol use increased from $44 \%$ to $48 \%{ }^{23}$ The NSDUH also showed that smoking menthols was more likely for recent initiates (started smoking within the past year) than for those who started smoking more than a year earlier among those aged $12-17(49 \%$ vs $44 \%)$ and $18-25(40 \%$ vs $36 \%) .{ }^{23}$ Studies focused on youths have found smoking menthol cigarettes is significantly associated with indicators of nicotine dependency. ${ }^{20} 21$

\section{TOBACCO COMPANIES MANIPULATED MENTHOL CONTENT TO REINFORCE SMOKING BEHAVIOUR AND ADDICTION}

Industry documents consistently demonstrate that the companies manipulate menthol's ability to mask the harshness, increase the ease of smoking and provide a cooling sensation to provide particular sensory effects. ${ }^{5} 12131617$ They use menthol's sensory effects to minimise the immediate negative effects of tobacco smoke (harshness, irritation) and superimpose positive attributes (coolness, smoothness) to make menthol cigarettes easier to inhale. ${ }^{517}$ These characteristics depend on the amount of menthol added to cigarettes, with even non-identifiable levels contributing to smoothness and a reduced harshness percei- ved by smokers. ${ }^{5}$ Beginning in the 1970 s, tobacco companies investigated the effects of adding different amounts of menthol to cigarettes and manipulated menthol levels to develop different cigarettes for young and experienced menthol smokers. ${ }^{12}$

In the early 1970s tobacco companies discovered that increased menthol levels affected the 'impact' or the 'grab' that smokers perceive in their throats when inhaling smoke that is essential for the immediate perception of strength and satisfaction. ${ }^{5} 16$ A 1989 Philip Morris study concluded that impact jointly depended on the levels of nicotine and menthol. ${ }^{16}$ Furthermore, company research beginning in 1995 found that menthol alone can increase impact, suggesting that menthol reinforces smoking behaviour independent of nicotine. ${ }^{24}$ Menthol's nicotine-like effects led several companies to conclude that menthol could be used to compensate for the reduced 'satisfaction' of low tar/nicotine yield cigarettes to increase their appeal. ${ }^{5}{ }^{16}$ Research done by Philip Morris in the 1980s even suggested that a menthol-like additive could be used as an analogue (substitute) for nicotine. ${ }^{5} 25$ Independent research confirmed different menthol levels in cigarettes depending on company-defined cigarette descriptors (eg, ultralight or light) or cigarette length (eg, $100 \mathrm{~mm}$ or $85 \mathrm{~mm}$ ). ${ }^{26}$ These results are consistent with tobacco company research suggesting that menthol is used to offset reduced delivery or impact in low tar/ nicotine, 'light' cigarettes.

Independent research confirms the companies' understanding that menthol's particular anaesthetic and sensory characteristics mask the immediate negative health effects of smoking ${ }^{4}$ and its potential interaction with nicotine. ${ }^{24}$ Independent research reported that menthol has analgesic, antitussive, antibacterial, antiallergic and soothing effects on the respiratory tract, as well as serving as an expectorate ${ }^{4}$ and reinforcing the effects of nicotine. ${ }^{27}$ An independent study of smokers' descriptions of early experiences with cigarettes found differences in African Americans' and white people's early smoking experiences, with African Americans, who disproportionately started smoking with menthols, reporting more positive and pleasurable experiences as opposed to reporting dizziness or difficulty inhaling. ${ }^{28}$ This work, combined with studies on the taste and rewarding effects of smoking menthols, suggest that menthol reinforced smoking, possibly leading to increased nicotine dependence. ${ }^{27}$

Independent research confirms the complex interaction between menthol and nicotine that the cigarette companies studied. Menthol smokers do not have significantly different Fagerström Test for Nicotine Dependence (FTND) scores than non-menthol smokers. ${ }^{27}{ }^{29-31}$ Nevertheless, studies have consistently found shorter time-to-first-cigarette in menthol smokers, ${ }^{20} 27$ 29-32 indicating higher levels of addiction. However, menthol smokers also consistently report smoking fewer cigarettes per day. ${ }^{31}{ }^{33}$ These two findings may help explain the FTND results, because the FTND depends on both time-to-first cigarette and number of cigarettes per day. These consistent but seemingly contradictory results suggest that there is a complex interaction between menthol and nicotine in terms of the cigarettes' addictive properties.

\section{TOBACCO COMPANY MARKETING ASSOCIATES MENTHOL CIGARETTES WITH MEDICINAL PROPERTIES AND IMPLIED HEALTH MESSAGES}

Early menthol cigarette brands (Spud, Kool) were introduced as a remedy for throat irritation, cough, allergies or heavy smoking. ${ }^{8}$ After menthol cigarettes were introduced in the 1920s tobacco companies' menthol cigarette advertising 
emphasised health benefits ${ }^{8}$ and connected them with medicinal remedies that commonly contain menthol, such as chest rubs and throat lozenges. ${ }^{6} 8$ Until the 1950s most menthol cigarettes were only smoked occasionally by smokers. ${ }^{6}$ This pattern was consistent with explicit health messages that presented menthol cigarettes as a healthier alternative to non-menthols to be used when smokers felt they temporarily needed a less harsh cigarette to relieve symptoms. ${ }^{6}$ A 1951 case report in the Journal of the American Medical Association reflected this widely accepted health messaging by referring to menthol cigarettes as 'medicated cigarettes', which the reporting physician observed that patients used for their 'anesthetic and cooling effect ... for rhinitis, pharyngitis, laryngitis, and bronchitis'. ${ }^{4}$

The public was becoming more worried about the dangers of cigarette smoke in 1952 when Reader's Digest printed an article entitled 'Cancer by the Carton'. ${ }^{35}$ By the mid-1950s the cigarette companies had stopped making explicit health claims in their advertising because they believed that such messaging reminded people of the association between smoking and cancer. ${ }^{6}$ During the 1980s, however, the companies continued to appreciate the continuing benefits of the association between menthol cigarettes and health established before the mid-1950s. ${ }^{8}$

After the public became more aware of, and concerned about smoking's health dangers menthol cigarette marketing shifted to more subtle health reassurance messages emphasising the positive experience of smoking menthols. ${ }^{8}$ By describing menthol cigarettes as 'clean', 'fresh', 'refreshing' and 'cool', tobacco marketing put the focus on the taste of menthols as a positive feature while still suggesting health benefits to reassure smokers. ${ }^{8}$ In the 1970s, British American Tobacco and its US subsidiary Brown and Williamson, described marketing goals for brand promotion to "convince smokers ... that Kent menthol is the menthol that offers refreshing menthol smoking satisfaction and health reassurance ${ }^{36}$ and to position the Kool menthol brand into the 'health reassurance segment'. ${ }^{15} 37$ After this shift to reassurance rather than explicit health claims, tobacco companies continued to recognise the importance of retaining a connection between menthol and health in the general public. For example, Brown and Williamson developed a 1979-1985 prime marketing objective for Kool menthol cigarettes to provide reassurance with the message that Kool cigarettes are 'safe' through the launch of a 'low-tar' or 'mild' product. ${ }^{8} 37$

Tobacco company research in the 1960 s and 1970 s consistently found that smokers perceive menthol cigarettes as healthier, safer, milder and less harmful. ${ }^{8} 38$ This effect seems to have faded with time. Independent research using the 2009 HealthStyles survey $^{39}$ and the 2005 New Jersey Adult Tobacco Survey ${ }^{40}$ showed few menthol smokers or respondents overall (smokers and non-smokers) believed that menthol cigarettes were less harmful than non-menthol cigarettes. Both studies also show younger respondents are more likely than older ones to report that menthol cigarettes are more harmful/risky. ${ }^{39} 40$ This age effect also appeared in a 2010 study using focus group and survey data to assess attitudes and beliefs about menthol cigarettes among African Americans: beliefs that menthol cigarettes have medicinal effects and are less harmful were most likely to be held by older smokers. ${ }^{41}$ These results may reflect the fact that older smokers were more likely to have been exposed to earlier industry advertisements promoting menthol's health 'benefits'.

\section{THE TOBACCO COMPANIES TARGETED VULNERABLE GROUPS FOR MENTHOL CIGARETTE PROMOTIONS}

In addition to youth, the cigarette companies targeted women and African Americans for menthol cigarettes. ${ }^{6} 8$ Independent research in the open literature confirms that smokers in these populations are more likely to smoke menthol cigarettes than others. $^{6} 742$

\section{Women}

Women were the first group targeted by tobacco companies for menthol use. By the 1950s most menthol smokers were women. ${ }^{6}$ After RJ Reynolds introduced Salem menthols in 1956, tobacco companies noted that female smokers liked the new filters, longer cigarettes and menthol flavour. ${ }^{6}$ Menthol cigarette advertising at the time used images of romance, beauty, nature, relaxation and female desirability to appeal to women. ${ }^{6}$ Tobacco companies disproportionately advertised menthols in women's magazines and on daytime television. For example, Brown and Williamson's 1969 Kool campaign to promote its extra-long menthol cigarettes was named 'Lady Be Kool' based on knowledge that female menthol smokers preferred extra-long cigarettes. ${ }^{6}$ Beginning in the 1980s and early 1990s, companies expanded targeted marketing of menthols to women in Japan, Korea and Singapore where menthol sales subsequently rose rapidly and brands have attracted high proportions of young women. $^{8} 9$

Confirming conclusions from tobacco industry documents, independent research demonstrates higher proportions of women continue to smoke menthol than non-menthol cigarettes. The higher prevalence of menthol smoking among women is confirmed by nationally representative surveys. According to the 2004-2008 National Survey on Drug Use and Health (NSDUH), over $52 \%$ of menthol smokers are female compared with 43\% for non-menthol. ${ }^{22} 23$ The 2003 and 2006-7 Tobacco Use Supplements to the Current Population Survey (TUS-CPS) show higher prevalence of menthol smoking among women aged $18+$ with $55 \%$ of menthol smokers being female compared with 44\% for non-menthol. ${ }^{7}$ The 2005 National Health Interview Survey and Cancer Control Supplement show that women are significantly more likely to be menthol smokers (25\% for white people, $78 \%$ for black people and $36 \%$ for Hispanic people) than men (15\% for white people, $70 \%$ for black people and $17 \%$ for Hispanic people) after adjusting for age, income and education. ${ }^{42}$ This pattern appears internationally. For example, survey data from Japan show that, by $2000,48 \%$ of female high-school smokers smoked menthols compared with $18 \%$ of males. ${ }^{9}$

\section{African Americans}

Before the 1960s, African Americans smoked menthol and non-menthol cigarettes at rates similar to the general population, and like the general population, most smoked non-menthol brands. ${ }^{6}$ In the following decades, tobacco companies competed for menthol market share and targeted inner cities predominantly composed of African American residents with menthol cigarette marketing during the late 1970s-1990s. ${ }^{43}$ The 2003 and 2006-7 TUS-CPS indicated that $74 \%$ of adult African American smokers smoked menthol cigarettes compared with $21 \%$ of non-Hispanic white people. ${ }^{7}$ This dramatic change in the proportion of African American menthol smokers coincided with cigarette company target marketing of menthol cigarettes to African Americans beginning in the 1960s. ${ }^{44}$

Tobacco companies used a variety of marketing methods to reach the African American market to increase sales, ${ }^{8} 144344$ including concentrating menthol cigarette advertisements in popular African American magazines and television programmes. $^{844}$ Tobacco companies found that African Americans were more likely than white people to trust advertising and 
promotional campaigns targeted at them. ${ }^{44}$ Company research found that in the 1960s and 1970s African Americans were more likely to believe health messaging related to menthol ${ }^{4}{ }^{44}$ and respond favourably to menthol marketing efforts to associate menthol cigarettes with African American culture. ${ }^{64}$ Tobacco companies reinforced conventional advertising campaigns in several ways. Tobacco companies formed organisational and philanthropic relationships with black community groups and civil rights organisations, ${ }^{45}$ developed tailored brands in the 1990s (such as RJ Reynolds' Uptown and an independent Boston firm's $\mathrm{X}^{44}{ }^{46}$ ) and targeted black urban neighbourhoods by distributing free menthol cigarettes using mobile vans in the 1980s and early 1990s, as well as using retailer incentive programmes. ${ }^{14} 43$

The independent literature confirms that these targeted marketing and public relations efforts were successful. The 2004-2008 National Survey on Drug Use and Health (NSDUH) indicated that $83 \%$ of African Americans aged 12 or older reported smoking menthol cigarettes in the past month compared with $24 \%$ of white people. ${ }^{23}$

Independent research on the receptivity of African Americans to tobacco industry health messaging on menthol has tended to find that African Americans are more likely to associate menthol cigarettes with reduced health risk, although research is mixed. Focus group and survey data collected in 2006 among African Americans in Los Angeles, California, show that African American menthol smokers had significantly higher measures of positive attitudes and beliefs regarding the medicinal effects and reduced harm of menthol cigarettes than non-menthol smokers by $10 \%$ and $9 \%$, respectively. ${ }^{41}$ Another study using data from the 2009 HealthStyles survey of US households found that African Americans are significantly more likely to believe that menthol cigarettes have health benefits compared to white people $(\mathrm{OR}=3.2,95 \%$ CI 1.8 to 5.7$) .{ }^{39}$ Similar findings have been published using interview data from African American smokers in Atlanta, Georgia, during 2005 showing that participants believed that smoking menthols leads to fewer negative health effects than smoking non-menthols. ${ }^{47}$ In contrast, one study using the 2005 New Jersey Adult Tobacco Survey found that African Americans overall were no more likely than other groups to believe that menthols are less risky than non-menthols and that current African American smokers were more likely to believe that menthols are more risky. ${ }^{40}$

\section{TOBACCO COMPANIES MANIPULATED MENTHOL CONTENT AND MARKETING TO DECREASE DESIRE TO OUIT AND INHIBIT CESSATION}

The tobacco documents show that the companies used and manipulated sensory characteristics of menthol cigarettes and health messaging in advertising to reassure smokers that menthol cigarettes were safer than non-menthols to assuage smokers' health concerns 6815 and probably contributed to decreased motivation of some smokers to quit. ${ }^{12}{ }^{15}$ Tobacco company research also identified declining social acceptability of smoking, particularly smokers' concern about how their secondhand smoke is perceived by and affects non-smokers, ${ }^{48} 49$ as one motivation for quitting that could be addressed by menthol's masking of tobacco odour. ${ }^{15}$

Health concerns have been repeatedly shown to be the primary reason that smokers quit, so masking irritation and immediate negative health effects of smoking potentially prevents cessation by providing a false sense of wellbeing and obscuring the health effects of smoking. ${ }^{4} 15$ The health messaging that tobacco companies used to associate menthol cigarettes with medicinal properties, ${ }^{6} 8$ manipulation of the soothing/cooling sensory effects of menthol that make them easier to inhale 17 and easier for new and young smokers to smoke ${ }^{11} 18$ all probably contributed to the perception among some smokers that menthol cigarettes are healthier than nonmenthol cigarettes and that menthols are a partial solution to the negative health effects of smoking. ${ }^{12} 15$

After the attention to the health effects of smoking that began in the 1950s, tobacco companies increased efforts to manufacture and market low-tar and low-nicotine cigarette brands. ${ }^{15}$ In the 1970s, company research showed that menthol cigarettes were considered by some to be a more flavourful, and yet mild, alternative to new non-menthol low-tar cigarettes, ${ }^{12}$ and the companies attributed the coincident growth of menthol brands like RJ Reynolds' Salem and Lorillard's Newport to this perception. ${ }^{15}$ Tobacco company studies found that many menthol smokers switched from non-menthols after smoking menthols when experiencing a cold when the harshness of non-menthol cigarettes was too irritating to their throats. ${ }^{8} 1215$ Tobacco company research on brand switching in the 1970 s found that menthol cigarettes experienced a $13 \%$ gain in market share as a result of switching to menthol brands from high filtration brands, compared with $8 \%$ for high filtration brands as a result of switching from menthol brands, showing that more smokers were switching to menthols than from them. ${ }^{15}$ Company focus group studies found that some menthol smokers had switched to menthols as an alternative to quitting, leading some company researchers in the 1960s through the 1980s to conclude that because menthol cigarettes were perceived as having less irritation and increased safety, they could be positioned as an alternative to quitting. ${ }^{8}{ }^{15}$ In 1979 , a report for Philip Morris supported this conclusion by finding that fewer menthol smokers report wanting to quit (39\%) than non-menthol smokers (43\%).

In the 1990s, tobacco companies also found that smokers were facing increased concern about secondhand smoke ${ }^{48} 49$ and that menthol cigarettes reduced the perception of offensive tobacco odour associated with smokers, thereby making smokers feel that smoking menthol cigarettes was more socially acceptable than non-menthol cigarettes both inside ${ }^{15}$ and outside ${ }^{9}$ the USA. This finding inspired a 1990 RJ Reynolds marketing strategy for its menthol brand Horizon that explicitly advertised an 'improved lingering aroma'. ${ }^{5}{ }^{50}$ Like other efforts to develop socially acceptable cigarettes, ${ }^{48}$ this idea was ultimately abandoned because it called attention to the negative perception of smoke odour. ${ }^{15}$ In addition, because menthol masks some of the characteristics of smoking, menthol cigarettes may be associated with the denial of personal identification as a 'smoker', ${ }^{12}$ which would mitigate conflict related to the social unacceptability of smoking

There are conflicting findings in the open literature on the effects of menthol on cessation and relapse, likely due to the use of different outcomes, measures, and types of studies, with more evidence indicating lower quit rates and higher relapse rates among menthol smokers. ${ }^{27}{ }^{51}$ A study of current smokers using the 2003 and 2006-7 TUS-CPS to assess cessation of menthol smoking found no significant relation between menthol and non-menthol cigarettes and quit attempts in the past year or length of smoking abstinence. ${ }^{31}$ However, other studies using the same 2003 and 2006-7 TUS-CPS showed that those who used to regularly smoke menthol cigarettes compared with non-menthol were less likely to quit. ${ }^{51} 52 \mathrm{One}^{52}$ found that menthol smokers were less likely to have quit for at least 6 months across racial groups (African Americans $\mathrm{OR}=0.23$; Asian American/Pacific Islander $\mathrm{OR}=0.22$; Hispanic $\mathrm{OR}=0.49$; 
Native American $\mathrm{OR}=0.49$; non-Hispanic white $\mathrm{OR}=0.28$ ). Another ${ }^{51}$ similarly found that menthol smokers are significantly less likely to have successfully quit than non-menthol smokers in the past year and in the past 5 years (adjusted $\mathrm{OR}=0.97$ and $\mathrm{OR}=0.94$, respectively). These different results may be because the first study ${ }^{31}$ was of current daily smokers while the second ${ }^{52}$ and third ${ }^{51}$ were of former smokers (smoked at least 100 cigarettes but did not smoke at the time of survey). Limiting the sample to current daily smokers may obscure differences in cessation success because it excludes smokers who were able to become non-daily users in attempts to quit. Without more specific information about successful quitting and smoking patterns among menthol smokers and non-menthol smokers it is difficult to assess this possibility. However, tobacco company studies identified a possible relation between menthol cigarettes and social smoking, suggesting that social smoking among menthol users was associated with someone who is not a 'real smoker' or who is trying to give up smoking. ${ }^{12}$

Research on menthol and cessation has consistently found that the association between menthol cigarette smoking and difficulty quitting is stronger among racial/ethnic minority groups, younger smokers and in studies done after $1999 .{ }^{53}$ The 2005 National Health Interview Study Cancer Control Supplement shows significant interaction effects between being African American and menthol use (interaction term adjusted $\mathrm{OR}=0.72$ ) in predicting population quit ratio (the total number of former smokers divided by the total number of individuals who had reported smoking in their lifetime). ${ }^{54}$ This result indicates that being African American and smoking menthol makes someone less likely to quit than just the additive effects of being African American and smoking menthols. The 2003 and 2006-7 TUS-CPS also showed that among African Americans (adjusted $\mathrm{OR}=1.62$ ) and Hispanics (adjusted $\mathrm{OR}=1.21$ ) smoking menthol cigarettes was significantly associated with seriously considering quitting and a positive estimation of successfully quitting (African American $\mathrm{OR}=1.87$ and Hispanic $\mathrm{OR}=1.34$ ). ${ }^{52}$ However, former menthol smokers in both groups were significantly less likely to have successfully quit compared with nonmenthol smokers for at least 6 months (African American $\mathrm{OR}=0.23$ and Hispanic $\mathrm{OR}=0.48$ ), suggesting that for African Americans and Hispanics menthol cigarettes may increase smokers' perception of the ease of quitting while, at the same time, undermining their success rates. ${ }^{52}$

\section{THE CIGARETTE COMPANIES AVOIDED CONDUCTING RESEARCH ON THE DISEASE-INDUCING EFFECTS OF MENTHOL, BUT DID FIND ADVERSE EFFECTS ON THE AMOUNT OF FINE PARTICLES IN THE SMOKE OF MENTHOLATED CIGARETTES}

Studies of tobacco industry documents did not locate much company research on the direct toxic effects of menthol. ${ }^{19}$ Instead, the companies concentrated on monitoring the (limited) independent research in this area and used it in internal and external briefing papers to argue that there were no direct adverse health effects of menthol. ${ }^{19}$ We only located two epidemiological studies of the association of smoking menthol cigarettes with disease, one on atherosclerosis and pulmonary function ${ }^{55}$ and one on oesophageal cancer, ${ }^{56}$ both of which reported no difference between smokers of menthol and non-menthol cigarettes. (The study of oesophageal cancer ${ }^{56}$ was from an individual with funding from the tobacco industry. ${ }^{57}$ )

These limited findings do not mean, however, that adding menthol to cigarettes does not have any direct negative health effects. Research conducted by the cigarette companies, ${ }^{19}$ some of which was published in the open literature ${ }^{58-61}$ consistently demonstrated that adding menthol to cigarettes increased the number of fine particles in the smoke by $10-20 \%$. Even at the low levels found in outdoor air pollution or secondhand smoke, which are much lower levels than delivered in active smoking, these fine particles have a direct adverse effect on cardiovascular morbidity and mortality and can trigger an acute cardiac event. ${ }^{62-66}$

\section{CONCLUSION}

The results of both internal tobacco company research and studies done in the independent scientific literature are remarkably consistent in showing that menthol influences much more than the taste of cigarette smoke. In addition to its candylike appeal, menthol's sensory effects and ability to mask irritation make menthol cigarettes appealing as a likely starter product. Youths disproportionately smoke menthols, in part because of these sensory characteristics and targeted marketing. Menthol marketing has also been targeted at groups (youths, women and African Americans) that have disproportionate percentages of menthol smokers. Menthol's sensory qualities may also make low-tar cigarettes more palatable and make it easier for inexperienced smokers to progress into increased exposure and, thus, reinforce dependence on nicotine.

Menthol's use for promoting cigarette smoking goes beyond its use as a flavouring, highlighted by the point that tobacco companies knew as early as 1972 that menthol enhances the perception of smoothness even at unidentifiable levels and in non-menthol cigarettes. The ubiquitous addition of menthol by tobacco companies to over $90 \%$ of all tobacco products, whether labelled 'menthol' or not, demonstrates that menthol is not simply a flavour or brand. Menthol imparts sensory characteristics to cigarettes and has a complex interaction with nicotine that affects smoking behaviour whether it is perceived or not, or whether cigarettes containing menthol are marketed as 'menthol' or not.

The consistency between industry marketing efforts and population use patterns of menthol cigarettes contradicts the conclusions in a 2010 review by a tobacco company scientist that research examining menthol's effects on smoking behaviour 'is not possible from survey data' because of 'social, demographic and peer influence mediators and confounders' ${ }^{67}$

Menthol facilitates and increases smoking, which causes disease and death. In developing regulations for tobacco products, the law directs the FDA to consider (i) the risks and benefits to the population as a whole; ... (ii) the increased or decreased likelihood that existing users of tobacco products will stop using such products; and (iii) the increased or decreased

\section{What this paper adds}

Tobacco companies have manipulated marketing and the content of menthol cigarettes to increase smoking and discourage cessation.

- Tobacco companies' knowledge and use of menthol in cigarettes are supported by findings in the open literature. Cigarette companies use the fact that menthol makes cigarettes easier to smoke to encourage initiation, reinforce addiction and complicate cessation. In addition, tobacco companies' marketing efforts associate menthol with health and targets vulnerable groups such as youths, women and African Americans. 
likelihood that those who do not use tobacco products will start using such products. ${ }^{1}$ The information in the industry documents, confirmed in the independent scientific literature, consistently demonstrates that menthol increases the population harm due to smoking because it increases initiation and reduces cessation in some groups. There also appear to be complex interactions with the addictive effects of nicotine. In addition, there is evidence suggesting that adding menthol increases harm by increasing fine particles in cigarette smoke, which have immediate adverse effects on the risk of a heart attack. Based on this large and consistent body of evidence, public health demands that the FDA and similar agencies outside the US ban all use of menthol, in not only cigarettes but also similar products such as cigars, cigarillos, and menthol sprays which are used with roll-your-own tobacco products, regardless of whether the menthol is used a characterizing taste or present at levels below sensory detection. These agencies should also recognize that menthol is used in smokeless products and likely has similar interactions with nicotine and ban such use until presented with compelling evidence that including menthol in these products is not producing similar harm as it does in smoked tobacco products.

Funding This research was funded by $\mathrm{NCl}$ grants CA-113710 and CA-87472. The funding agency played no role in the selection of topic, conduct of the research or preparation of the manuscript.

Competing interests None.

Contributors Both authors worked together to draft the manuscript.

Provenance and peer review Not commissioned; externally peer reviewed.

\section{REFERENCES}

1. Family Smoking Prevention and Tobacco Control Act P.L. 111-31, 123 Stat. 1776. 2009.

2. Califano J, Sullivan LW, Shalala DE, et al. Letter to Representatives and Senators re: the Family Smoking Prevention and Tobacco control Act. of Document. 2008. Source. http://www.nytimes.com/2008/06/05/business/05TobaccoLetter.html? $r=1$ gref $=$ business (Estimated).

3. $\bar{R}$ eid JR. A History of Mentholated Cigarettes 'This Spud's for You': Philip Morris, 1993. http://legacy.library.ucsf.edu/tid/nqf32e00.

4. Garten S, Falkner RV. Continual smoking of mentholated cigarettes may mask the early warning symptoms of respiratory disease. Prev Med 2003;37:291-6.

5. Ferris Wayne G, Connolly GN. Application, function, and effects of menthol in cigarettes: a survey of tobacco industry documents. Nicotine Tob Res 2004;6/Suppl 1):S43-54.

6. Sutton CD, Robinson RG. The marketing of menthol cigarettes in the United States: populations, messages, and channels. Nicotine Tob Res 2004;6(Suppl 1):S83-91.

7. Lawrence D, Rose A, Fagan $P$, et al. National patterns and correlates of mentholated cigarette use in the United States. Addiction 2010:105(Suppl 1):13-31.

8. Anderson SJ. Marketing of menthol cigarettes and consumer perceptions: a review of tobacco industry documents. Tobacco Control 2011;20(Suppl 2):ii20-ii28.

9. Connolly GN, Behm I, Osaki Y, et al. The impact of menthol cigarettes on smoking initiation among non-smoking young females in Japan. Int $J$ Environ Res Public Health 2011:8:1-14.

10. Smith LB. FDA Regulation of the Tobacco Industry: RJ Reynolds, December 6. http:// legacy.library.ucsf.edu/tid/jot81b00.

11. Kreslake JM, Wayne GF, Alpert HR, et al. Tobacco industry control of menthol in cigarettes and targeting of adolescents and young adults. Am J Public Health 2008;98:1685-92

12. Kreslake JM, Wayne GF, Connolly GN. The menthol smoker: tobacco industry research on consumer sensory perception of menthol cigarettes and its role in smoking behavior. Nicotine Tob Res 2008;10:705-15.

13. Kreslake JM, Yerger VB. Tobacco industry knowledge of the role of menthol in chemosensory perception of tobacco smoke. Nicotine Tob Res 2010;12(Suppl 2): S98-101.

14. Cruz TB, Wright LT, Crawford G. The menthol marketing mix: targeted promotions for focus communities in the United States. Nicotine Tob Res 2010;12(Suppl 2): S147-53.

15. Anderson SJ. Menthol cigarettes and smoking cessation behavior: a review of tobacco industry documents. Tobacco Control 2011;20(Suppl 2):ii49-ii56.

16. Yerger VB. Menthol's potential effects on nicotine dependence: a tobacco industry perspective. Tobacco Control 2011;20(Suppl 2):ii29-ii36.

17. Yerger VB, McCandless PM. Menthol sensory qualities and smoking topography: a review of the tobacco industry documents. Tobacco Control 2011;20(Suppl 2): ii37-ii43.
18. Klausner K. Menthol cigarettes and smoking initiation: a tobacco industry perspective. Tobacco Control 2011;20(Suppl 2):ii12-ii19.

19. Salgado VM, Glantz SA. Direct disease-inducing effects of menthol through the eyes of tobacco companies. Tobacco Control 2011:20(Suppl 2):ii44-ii48.

20. Hersey JC, Ng SW, Nonnemaker JM, et al. Are menthol cigarettes a starter produc for youth? Nicotine Tob Res 2006:8:403-13.

21. Hersey JC, Nonnemaker JM, Homsi G. Menthol cigarettes contribute to the appea and addiction potential of smoking for youth. Nicotine Tob Res 2010;12(Suppl 2): S136-46.

22. Rock VJ, Davis SP, Thorne SL, et al. Menthol cigarette use among racial and ethnic groups in the United States, 2004-2008. Nicotine Tob Res 2010;12(Suppl 2):S117-24.

23. Anon. Substance Abuse and Mental Health Services Administration, Office of Applied Studies. Rockville, MD: The NSDUH Report: Use of Menthol Cigarettes, 2009.

24. Ahijevych K, Garrett BE. Menthol pharmacology and its potential impact on cigarette smoking behavior. Nicotine Tob Res 2004;6(Suppl 1):S17-28.

25. Gullotta FP. A Menthol Analogue for Low Delivery Non-Menthol Cigarettes: Philip Morris, May 9. http://legacy.library.ucsf.edu/tid/vio46b00.

26. Celebucki CC, Wayne GF, Connolly GN, et al. Characterization of measured mentho in 48 U.S. cigarette sub-brands. Nicotine Tob Res 2005; 7:523-31.

27. Ahijevych K, Garrett BE. The role of menthol in cigarettes as a reinforcer of smoking behavior. Nicotine Tob Res 2010;12(Suppl 2):S110-16.

28. Finkenauer R, Pomerleau CS, Snedecor SM, et al. Race differences in factors relating to smoking initiation. Addict Behav 2009:34:1056-9.

29. Muscat JE, Chen G, Knipe A, et al. Effects of menthol on tobacco smoke exposure nicotine dependence, and NNAL glucuronidation. Cancer Epidemiol Biomarkers Prev 2009:18:35-41.

30. Okuyemi KS, Ahluwalia JS, Ebersole-Robinson M, et al. Does menthol attenuate the effect of bupropion among African American smokers? Addiction 2003;98:1387-93

31. Fagan $\mathbf{P}$, Moolchan ET, Hart A Jr, et al. Nicotine dependence and quitting behaviors among menthol and non-menthol smokers with similar consumptive patterns. Addiction 2010;105(Suppl 1):55-74.

32. Wackowski $\mathbf{0}$, Delnevo CD. Menthol cigarettes and indicators of tobacco dependence among adolescents. Addict Behav 2007:32:1964-9.

33. Mendiondo MS, Alexander LA, Crawford T. Health profile differences for mentho and non-menthol smokers: findings from the National Health Interview Survey. Addiction 2010;105(Suppl 1):124-40.

34. Highstein B, Zeligman I. Nonthrombocytopenic purpura caused by mentholated cigarettes. J Am Med Assoc 1951:146:816.

35. Glantz SA. The Cigarette Papers. Berkeley: University of California Press, 1996.

36. Lorillard. Kent Menthol 100's: Lorillard. http://legacy.library.ucsf.edu/tid/ dud20e00.

37. Lorillard. Kool Family Utopian Objectives 1979-1985. Research. http://legacy. library.ucsf.edu/tid/xim66b00.

38. Giovino GA, Sidney S, Gfroerer JC, et al. Epidemiology of menthol cigarette use. Nicotine Tob Res 2004;6(Suppl 1):S67-81.

39. Davis SP, McClave-Regan AK, Rock VJ, et al. Perceptions of menthol cigarette use among U.S. adults and adult smokers: findings from the 2009 HealthStyles survey. Nicotine Tob Res 2010;12(Suppl 2):S125-35.

40. Wackowski OA, Delnevo CD, Lewis MJ. Risk perceptions of menthol cigarettes compared with nonmenthol cigarettes among New Jersey adults. Nicotine Tob Res 2010;12:786-90.

41. Allen B Jr, Cruz TB, Leonard E, et al. Development and validation of a scale to assess attitudes and beliefs about menthol cigarettes among african american smokers. Eval Health Prof 2010;33:414-36.

42. Cubbin C, Soobader MJ, LeClere FB. The intersection of gender and race/ethnicity in smoking behaviors among menthol and non-menthol smokers in the United States. Addiction 2010;105(Suppl 1):32-8.

43. Yerger VB, Przewoznik J, Malone RE. Racialized geography, corporate activity, and health disparities: tobacco industry targeting of inner cities. J Health Care Poor Underserved 2007:18/4 Suppll):10-38.

44. Gardiner PS. The African Americanization of menthol cigarette use in the United States. Nicotine Tob Res 2004;6(Suppl 1):S55-65.

45. Yerger VB, Malone RE. African American leadership groups: smoking with the enemy. Tob Control 2002;11:336-45

46. Balbach ED, Gasior RJ, Barbeau EM. R.J. Reynolds' targeting of African Americans 1988-2000. Am J Public Health 2003:93:822-7.

47. Richter P, Beistle D, Pederson L, et al. Small-group discussions on menthol cigarettes: listening to adult African American smokers in Atlanta, Georgia. Ethn Health 2008;13:171-82.

48. Ling PM, Glantz SA. Tobacco industry consumer research on socially acceptable cigarettes. Tob Control 2005:14:e3.

49. Schane RE, Glantz SA, Ling PM. Social smoking implications for public health, clinical practice, and intervention research. Am J Prev Med 2009;37:124-31.

50. Young Rubicam. Horizon Strategic Marketing Review: RJ Reynolds, October 1. http://legacylibraryucsfedu/tid/yzt03a00.

51. Levy D, Blackman K, Tauras JA, et al. Quit attempts and quit rates among mentho and non-menthol smokers: findings from a national population survey. Am J Public Health. In press

52. Trinidad DR, Perez-Stable EJ, Messer K, et al. Menthol cigarettes and smoking cessation among racial/ethnic groups in the United States. Addiction 2010;105/Suppl 1):84-94. 
53. Foulds J, Hooper MW, Pletcher MJ, et al. Do smokers of menthol cigarettes find it harder to quit smoking? Nicotine Tob Res 2010;12(Suppl 2):S102-9.

54. Stahre M, Okuyemi KS, Joseph AM, et al. Racial/ethnic differences in menthol cigarette smoking, population quit ratios and utilization of evidence-based tobacco cessation treatments. Addiction 2010;105(Suppl 1):75-83

55. Pletcher MJ, Hulley BJ, Houston T, et al. Menthol cigarettes, smoking cessation, atherosclerosis, and pulmonary function: the Coronary Artery Risk Development in Young Adults (CARDIA) Study. Arch Intern Med 2006;166:1915-22.

56. Hebert JR, Kabat GC. Menthol cigarette smoking and oesophageal cancer. Int J Epidemiol 1989;18:37-44.

57. Bero LA, Glantz S, Hong MK. The limits of competing interest disclosures. Tob Control 2005:14:118-26.

58. Carmines EL. Evaluation of the potential effects of ingredients added to cigarettes Part 1: cigarette design, testing approach, and review of results. Food Chem Toxicol 2002:40:77-91.

59. Baker RR, Massey ED, Smith G. An overview of the effects of tobacco ingredients on smoke chemistry and toxicity. Food Chem Toxicol 2004;42 (Suppl):S53-83

60. Baker RR, Pereira da Silva JR, Smith G. The effect of tobacco ingredients on smoke chemistry. Part II: casing ingredients. Food Chem Toxicol 2004;42(Suppl): S39-52.
61. Rustemeier K, Stabbert R, Haussmann HJ, et al. Evaluation of the potential effects of ingredients added to cigarettes. Part 2: chemical compositino of mainstream smoke. Food Chem Toxicol 2002; 40:93-104.

62. Brook RD, Franklin B, Cascio W, et al. Air pollution and cardiovascular disease: a statement for healthcare professionals from the Expert Panel on Population and Prevention Science of the American Heart Association. Circulation 2004;109:2655-71.

63. Pope CA 3rd, Burnett RT, Thurston GD, et al. Cardiovascular mortality and long-term exposure to particulate air pollution: epidemiological evidence of general pathophysiological pathways of disease. Circulation 2004:109:71-7.

64. Pope CA 3rd, Burnett RT, Krewski D, et al. Cardiovascular mortality and exposure to airborne fine particulate matter and cigarette smoke: shape of the exposure-response relationship. Circulation 2009:120:941-8.

65. Brook RD, Rajagopalan S, Pope CA 3rd, et al. Particulate matter air pollution and cardiovascular disease: an update to the scientific statement from the American Heart Association. Circulation 2010;121:2331-78.

66. Institute of Medicine Committee on Secondhand Smoke Exposure and Acute Coronary Events. Secondhand Smoke Exposure and Cardiovascular Effects: Making Sense of the Evidence. Washington, DC: National Academies Press, 2010.

67. Heck JD. A review and assessment of menthol employed as a cigarette flavoring ingredient. Food Chem Toxicol 2010;48(Suppl 2):S1-38. 